\title{
PROPUESTAS DE MEJORA DE TRABAJO EN CASOS DE ABSENTISMO ESCOLAR EN EDUCACIÓN PRIMARIA
}

Coronel Garrido, Raquel; Díaz García, Melody; Moreno Leal, Patricia. Universidad de Huelva

\section{RESUMEN}

Partiendo del concepto de absentismo escolar, de la normativa existente y de las responsabilidades que atañen a la familia y a los poderes públicos, se describen las características personales y sociales de niños absentistas. Además se hará un abordaje de la tipología más actual en la que se clasifica el absentismo y sus posibles causas, expuestas por diferentes autores. Derivado de esto, se proponen diferentes actuaciones para combatir el absentismo escolar en primaria, ya que este, es uno de los momentos claves en los comienza a darse este problema, por lo que es necesaria una mayor atención en este tramo escolar, centrada en la prevención.

Palabras claves: Absentismo escolar, familia, escuela, fracaso escolar.

\section{INTRODUCCIÓN}

Según Melendro (2008), "El absentismo escolar se entiende como la asistencia irregular, o las ausencias repetidas e injustificadas del centro educativo, de los menores en edad de escolarización obligatoria, o su no escolarización en este periodo."(p. 67). Este absentismo puede derivar en la salida anticipada del menor del sistema educativo, el denominado abandono escolar prematuro. $Y$ a su vez tener efectos sobre el rendimiento escolar, provocando retraso y, en las situaciones más graves, fracaso escolar. Una situación que supone dejar el sistema educativo antes de haber logrado adquirir un nivel apropiado de conocimientos. Por lo que el absentismo escolar, comienza siendo "un problema educativo que afecta a la comunidad escolar y pasa a ser un problema social, familiar y cultural". La no adquisición de los aprendizajes necesarios, requeridos para su futura inserción laboral y social por parte de los jóvenes que abandonaron prematuramente el sistema educativo, tiene efectos muy significativos a todos los niveles -social, emocional, competencial, económico- en el tipo de tránsito que estos realizan a la vida adulta. $Y$ genera situaciones de desigualdad y exclusión social.

A continuación, se exponen los diferentes tipos de absentismo escolar, además de sus posibles causas e intervenciones. Respecto a los distintos tipos de absentismo escolar según la clasificación que nos ofrece, Álvarez Castro (2009):

\section{TIPOS}

Injustificado:

El centro escolar no recibe ningún certificado en el que se exponga los motivas de la ausencia del alumno. 


\begin{tabular}{|l|l|}
\hline Puntual o esporádico: & $\begin{array}{l}\text { El alumno se ausenta de clase falta durante } \\
\text { un periodo de tiempo considerable pero } \\
\text { luego se reincorpora al centro sin volver a } \\
\text { repetirse tal ausencia. }\end{array}$ \\
\hline Intermitente: & $\begin{array}{l}\text { La asistencia se produce de forma alterna, } \\
\text { es decir, el alumno se ausenta por periodos } \\
\text { breves. }\end{array}$ \\
\hline Desescolarización: & $\begin{array}{l}\text { No estar escolarizado en la educación } \\
\text { obligatoria. }\end{array}$ \\
\hline Abandono prematuro: & $\begin{array}{l}\text { Alumno que cursa la educación obligatoria y } \\
\text { después de haber superado varias etapas } \\
\text { educativas decide dejar su formación } \\
\text { académica. }\end{array}$ \\
\hline
\end{tabular}

Tabla 1: Tipologías del Absentismo Escolar. (Álvarez Castro, 2009)

Por otro lado, se muestran las posibles causas del Absentismo escolar, conforme a distintos autores:

Según Melendro (2008), el absentismo escolar puede producirse por múltiples causas; se trata de un problema complejo que se focaliza en los centros educativos, aunque puede tener su origen en aspectos diferentes, como pueden ser desde el propio entorno escolar hasta el círculo familiar, el entorno social y cultural, las relaciones entre iguales..., por lo que se requiere de un abordaje interdisciplinar, complejo, donde los diferentes agentes sociales y educativos, como los padres, educadores, profesores, etc., deben trabajar en equipo para obtener resultados satisfactorios.

Además, se afirma que la escuela no es capaz, por sí misma, de solucionar los complejos problemas de la población infantil. Para ello propone que entre las posibles causas de absentismo escolar, se encuentra (Petrus; 2009):

- Ausencia de motivación hacia el estudio

- Entorno poco estimulado, en el que es frecuente el desinterés respecto al desarrollo escolar

- Dificultades económicas

- Carencia de recursos personales, sociales, competenciales,...

- Sensación de inutilidad, fracaso y desinterés hacia lo educativo que tiene lugar entre el grupo de iguales, etc.

- Modelos escolares poco flexibles

Asimismo, Racionero y Padrós (2010), no atribuye una única causa que afecte al absentismo; siendo, para estos autores, las más frecuentes:

- Pertenecer a etnia gitana

- Padre y madre trabajando fuera de casa

- Familias mono-parentales

- Bajo nivel cultural de los padres

- Conflicto entre las expectativas de los jóvenes para su futuro y lo que el sistema educativo les reporta para alcanzarlo

- Bajo nivel de comprensión de algunos alumnos con respecto a sus compañeros, por lo que se sienten mal en las aulas 
Por último, Aguado (2005) hace una clasificación de todas las posibles causas del absentismo en tres grandes grupos:

- Entre las causas familiares se destaca como una causa decisiva la situación familiar difícil (familias numerosas, mono-parentales, en situación desestructurada)

- Entre las causas sociales se acentúa la presencia de modelos absentistas en el entorno, falta de referentes académicos con éxito en la familia o entorno próximo, ausencia de recursos y estimulación para el estudio, etc.

- Entre las causas educativas se encuentra la escolarización tardía, así como la insuficiencia en ocasiones, de recursos organizativos, humanos y materiales.

En definitiva, derivado de todo lo anterior se puede decir que el absentismo escolar no cuenta con una única causa, puesto que son diversos los factores que influyen en esta problemática.

\section{PROPUESTA DE INTERVENCIÓN}

Debido a que el abandono escolar temprano tiene múltiples causas y se produce fruto de muy diferentes trayectorias, las medidas que lo previenen coinciden, en parte, con las estrategias que favorecen las expectativas positivas hacia el estudio, la autoestima, el éxito y el rendimiento escolar. (Consortium INCLUD-ED, 2009). Por lo que se procede a una revisión de algunas de las actuaciones que se han realizado respecto al tema.

El Plan Integral para la Prevención, Seguimiento y Control del Absentismo escolar (2003), recoge que el carácter integral de las actuaciones es una condición básica para mejorar las condiciones socioeconómicas y culturales que suelen estar en la base del absentismo escolar. Por ese motivo, se hace imprescindible el desarrollo de actuaciones no solo en el campo educativo y familiar sino también en el ámbito de los servicios sociales, la salud, el empleo y la formación y, en general, de cuantos aspectos mejoren las condiciones sociales y económicas del entorno. (Plan Integral para la Prevención, Seguimiento y Control del Absentismo Escolar, 2003)

De acuerdo a dicho Plan, las áreas de actuación en Absentismo escolar son (Plan Integral para la Prevención, Seguimiento y Control del Absentismo Escolar, 2003):

Prevención e Intervención en el ámbito escolar. Se pretende favorecer la adaptación del proceso de enseñanza a las necesidades e intereses de la población escolar que se encuentre en riesgo de iniciar o mantenerse en una situación de absentismo escolar. La implicación de los equipos directivos de los centros escolares, así como de los equipos y departamentos de orientación y del Servicio de Inspección constituye la pieza fundamental de las actuaciones que se desarrollen en esta área.

Atendiendo al modelo inclusivo, se potencia que diversos recursos humanos (profesorado, pero también diferentes especialistas, personas de la comunidad, etc.) estén en el aula favoreciendo que el alumnado con dificultades específicas participe en la actividad y potenciando las interacciones entre el alumnado con diferentes niveles de rendimiento, en la perspectiva de las actuales teorías de aprendizaje basadas en el diálogo y la interacción (Racionero y Padrós, 2010). 
Intervención en el ámbito social y familiar. Se recoge que las medidas programadas en esta área tenderán a lograr la intervención psicosocial con las familias en las que se detecte que sus condiciones de vida, costumbres y cultura se encuentran en el origen del absentismo de los menores con objeto de implicarlas y comprometerlas en la asistencia regular a los centros. La actuación de los Servicios Sociales Municipales dependientes de los Ayuntamientos y las Diputaciones constituyen el elemento clave de las medidas incluidas en esta área, sin olvidar el papel que en este ámbito corresponde a los Servicios Sociales Especializados.

La participación educativa, por tanto, consiste en la implicación de las familias y otros miembros de la comunidad bien en el proceso de aprendizaje de los alumnos, bien en su propia formación como personas adultas dentro del centro; de esta manera, se convierten en recursos humanos de apoyo al aprendizaje con un valor añadido como referentes positivos para sus propios hijos, o alumnado del mismo grupo social. (Martínez y Niemela, 2010).

Formación e Integración laboral. Las medidas incluidas en esta área tenderán a completar la formación de los jóvenes mediante acciones formativas ajustadas a sus necesidades e intereses, con objeto de facilitar su inserción social y laboral, tales como Programas de Cualificación Profesional e Inicia (PCPT), Escuelas Taller, Casas de Oficios y Cursos de Formación Ocupacional y programas o iniciativas europeas relacionadas con los objetivos del Plan.

Formación y Coordinación. Las medidas incluidas en esta área recogerán iniciativas tendentes a favorecer la formación y coordinación entre los diferentes profesionales implicados en el desarrollo del Plan. Igualmente en esta área se recogerán los dispositivos de coordinación de ámbito autonómico, provincial y local que se requieran para el desarrollo de las actuaciones con intervención de todas las Administraciones implicadas.

Por último, se proponen diferentes ejemplos de algunas de las actuaciones educativas de éxito que se llevan a cabo según distintos autores:

Las comisiones mixtas son una forma de organización básica y una manera de avanzar hacia la calidad educativa a través de la participación (Flecha y García, 2008). Se trata de comisiones formadas por personas de diferentes perfiles de la comunidad educativa: profesorado, familiares, alumnado, otros agentes; para cada una de los objetivos o cuestiones que se han considerado prioritarios se constituye una comisión mixta (Folch y Parents' Association, 2004)

Voluntariado: se consigue a través de personas a las que se invita a participar voluntariamente en la escuela. Estas personas son tan diversos como se pueda: en primer lugar, se valora la participación de las propias familias o personas del entorno inmediato; además, participan también - en diversos casos, a través de convenios con universidades o con entidades del entorno - estudiantes universitarios, profesionales y otros perfiles (Vieira, 2010).

El valor de este voluntariado no reside solamente en la posibilidad de contar con un mayor número de recursos humanos, sino en la riqueza de su pluralidad y la inteligencia cultural que se aporta (Ramis y Krastrina, 2010).

Bibliotecas tutorizadas: el alumnado, pero también otras personas del entorno, pueden utilizar la biblioteca para leer cuentos, para hacer deberes o resolver tareas escolares, buscar información en internet, etc.; la actividad propia de las bibliotecas, la 
lectura, queda potenciada en un sentido comunitario y colectivo. En ese espacio transformado, la lectura es algo a compartir con diferentes personas, en una práctica de lectura dialógica (Aguilar, Alonso, Padrós y Pulido, 2010).

\section{CONCLUSIÓN}

Haciendo referencia a todas las posibles causas descritas anteriormente, se puede decir que la problemática del absentismo está ligada a múltiples factores personales, sociales, familiares, económicos, así como también a otros de carácter educativo y relacionado con el funcionamiento y organización de los centros escolares; por lo que resultaría importante políticas destinadas a paliar el absentismo y abandono escolar.

Derivado del factor multidisciplinar que presenta el absentismo, cabe decir que su intervención debe recoger el carácter integral de todas las actuaciones que se lleven a cabo para paliar el problema; ya que esas actuaciones no sólo se limitan al campo educativo y familiar sino también al ámbito de los servicios sociales, la salud, el empleo y la formación y, en general, de cuantos aspectos mejoren las condiciones sociales y económicas del entorno.

\section{BIBLIOGRAFÍA}

Aguado, P. (2005). Programa de prevención y control del absentismo escolar en el Ayuntamiento de Madrid. Indivisa: Boletín de estudios e investigación, n 6, 249-257.

Aguilar, C., Alonso, J., Padrós, M., y Pulido, M. (2010). Lectura dialógica y transformación en las comunidades de aprendizaje. Revista Interuniversitaria de Formación del Profesorado, 67(24 (1)), 31-44.

Álvarez Castro, E. (2009). Absentismo escolar. Revista digital enfoques educativos. Pag 22-27.

Consortium INCLUD-ED. ( 2009). Actions for success in schools in Europe. Brussels: European Comission.

Flecha, R., y García, R. (2008). Garantizar el éxito con la incorporación de las familias. De la fiscalización y la descalificación a la colaboración. Organización y Gestión Educativa, 16(5), 23 - 26.

Folch, X., y Parents' Association. (2004). Romani families transforming the school. Networks: An on-Line Journal for Teacher Research, 7(1).

Martínez, B., y Niemela, R. (2010). Formas de participación de las familias y de la comunidad hacia el éxito educativo. Revista Educación y Pedagogía, 56, 69-78.

Melendro, M. (2008). Absentismo y fracaso escolar: la educación social como alternativa. Bordón. Revista de pedagogía. Vol. 60, nº 4, 65-77.

Plan Integral para la Prevención, Seguimiento y Control del Absentismo Escolar (2003). Acuerdo de 25 de Noviembre, por el que se aprueba el Plan Integral para la 
Prevención, Seguimiento y Control del Absentismo escolar. (Publicado en BOJA $n^{\circ}$ 235, de 5 de Diciembre de 2003).

Petrus, A. (2009). Nuevos ámbitos en educación social. En Romans, M.,Petrus, A. y Trilla, J. De profesión: educador social. Barcelona: Paidós, 63-147.

Racionero, S., y Padrós, M. (2010). The dialogic turn in educational psychology. Revista De Psicodidáctica, 15(2), 143-162.

Ramis, M., y Krastrina, L. (2010). Cultural intelligence in the school. Revista De Psicodidáctica, 15(2), 239-252.

Vieira, L. (2010). Voluntariado en la escuela: Un estudio de casos dentro del proyecto comunidades de aprendizaje. Tesis doctoral no publicada. Universidad de Barcelona. 